\title{
MR-guided focused ultrasound cerebellothalamic tractotomy for chronic therapy-resistant essential tremor: anatomical target reappraisal and clinical results
}

\author{
Marc N. Gallay, MD, David Moser, BSc, and Daniel Jeanmonod, MD \\ SoniModul, Center for Ultrasound Functional Neurosurgery, Solothurn, Switzerland
}

\begin{abstract}
OBJECTIVE In addition to the well-recognized ventral intermediate nucleus (Vim) thalamotomy for the treatment of chronic therapy-resistant essential tremor (ET), an alternative approach targeting the posterior part of the subthalamus was proposed in the 1960s and early 1970s and then was reactualized as cerebellothalamic tractotomy (CTT) with the advent of MR-guided focused ultrasound (MRgFUS) surgery. The goal of this study was to improve target coverage and thus efficacy (i.e., tremor control and its consistency). The authors undertook a histological reappraisal of the CTT target and proposed a targeting strategy of the MRgFUS CTT based on 1) the MR visualization of the center of the red nucleus and 2) the application of preplanned target subunits realized with short sonications under thermal dose control. This study was aimed at demonstrating the efficacy and risk profile of this approach against chronic therapy-resistant ET.

METHODS Ten consecutive patients suffering from chronic therapy-resistant ET benefited from a unilateral MRgFUS CTT and were followed over the course of 1 year. Primary endpoints were subjective tremor relief, Clinical Rating Scale for Tremor (CRST) score, activities of daily living (ADL) score, and the hand function (HF) scores HF16 and HF32. Histological reappraisal of the target led the authors to propose a standardized targeting protocol for MRgFUS CTT. Thermal doses for 18 and 240 cumulative equivalent minutes at $43^{\circ} \mathrm{C}$ were calculated and correlated with intraoperative and 2 days postoperative T2-weighted MR images.
\end{abstract}

RESULTS The mean \pm SD for the baseline CRST score was $48 \pm 12$; the score was $16 \pm 7$ at 3 months, and $17 \pm 8$ at 1 year. The mean tremor relief rated by the patients for the operated side was $95 \%$ after 2 days, $96 \%$ at 3 months, and $93 \%$ at 1 year. The mean HF16 was $11.0 \pm 2.1$ at baseline, $0.7 \pm 0.7$ at 3 months, and $0.8 \pm 0.9$ at 1 year $(93 \%$ mean reduction). The minimum reduction for the HF16 at 1 year was $78 \%$. There was a $51 \%$ reduction of the mean ADL score at 1 year. There was no bleeding or infection. Gait difficulties, only detectable on tandem gait, were increased in 3 patients and reduced in 2 patients at 1 year. There was no dysarthria.

CONCLUSIONS The authors' results suggest that MRgFUS CTT is a very effective treatment option for therapy-resistant ET.

https://thejns.org/doi/abs/10.3171/2019.12.JNS192219

KEYWORDS essential tremor; cerebellothalamic tractotomy; MR-guided focused ultrasound; functional neurosurgery; cumulative equivalent minutes; incisionless

$\mathrm{I}$ $\mathrm{N}$ addition to the well-recognized thalamotomy in the ventral intermediate nucleus (Vim of Hassler, corresponding to the posterior part of the thalamic ventral lateral nucleus [VLp]) for the treatment of chronic therapy-resistant essential tremor (ET), an alternative approach targeting the posterior part of the subthalamus was proposed in the 1960s and early $1970 \mathrm{~s} .4,5,22,40$ We undertook a reactualization of this approach, named cerebellothalamic tractotomy (CTT), first with radiofrequency ablation ${ }^{26,28}$ and later with MR-guided focused ultrasound (MRgFUS) surgery. ${ }^{19,20}$

There is sound histological evidence that the posterior part of the subthalamus, also named prelemniscal radiation by Hassler, ${ }^{21}$ field $\mathrm{H}$ by Forel,,${ }^{14}$ or caudal zona incerta,,${ }^{15}$ includes mainly the cerebellothalamic (or dentatothalamic) fiber tract on its way to the VLp..$^{16,31}$ This has allowed us to

ABBREVIATIONS ADL = activities of daily living; $\mathrm{CEM}=$ cumulative equivalent minutes; $\mathrm{CLT}=$ central lateral thalamotomy; $\mathrm{CMT}=$ centrum medianum thalamotomy; CRST = Clinical Rating Scale for Tremor; CTT = cerebellothalamic tractotomy; ET = essential tremor; HADS = Hospital Anxiety and Depression Scale; HF = hand function; ICP = intercommissural plane; MoCA = Montreal Cognitive Assessment; MRgFUS = MR-guided focused ultrasound; $\mathrm{mRN}=$ center of the red nucleus; mtt = mammillothalamic tract; PD = Parkinson disease; STN = subthalamic nucleus; Vim = ventral intermediate nucleus; VLp = posterior part of the thalamic ventral lateral nucleus; VPMpc = ventral posterior medial nucleus, parvocellular division; WHOQOL-BREF = World Health Organization Quality of Life questionnaire.

SUBMITTED September 20, 2019. ACCEPTED December 2, 2019.

INCLUDE WHEN CITING Published online February 7, 2020; DOI: 10.3171/2019.12.JNS192219. 
attribute a central role for this tract in the pathophysiology of ET.20

Although favorable in terms of safety and accuracy, ${ }^{13,19}$ the clinical results obtained with the MRgFUS technique regarding unilateral tremor control have shown some degree of variability or limitations. . $^{8,910,20,35,37,39,43}$ Indeed, in our first case series published on the MRgFUS CTT, ${ }^{20}$ the mean unilateral and bilateral tremor reductions stood at more than $70 \%$ for the treated side, but significant differences were seen between patients. Similar results were reported by another group..$^{37}$

To improve target coverage and thus efficacy (i.e., tremor control and its consistency), we undertook a histological reappraisal of the CTT target and proposed a targeting strategy based on 1) the MR visualization of the center of the red nucleus (mRN) and 2) the application of preplanned target subunits realized with short sonications under thermal dose control.

\section{Methods Ethics}

All patients treated with this protocol signed an informed consent document after being fully informed about the treatment, its results, and its risks. No additional ethical approval was sought because MRgFUS interventions for ET are approved and supervised by the Swiss Federal Office of Public Health (FOPH) as part of a dedicated national registry.

\section{Context of This Study}

There was no patient randomization and no blinding. This single-center consecutive case series reflects our current treatment routine of MRgFUS CTT for chronic therapy-resistant ET. There were no patients in this study who were part of the series published in 2016 by Gallay et al. ${ }^{20}$ Monitoring for primary outcome measures, adverse events, and cognitive evaluations was performed 2 days, 3 months, and 1 year after the procedure.

\section{Inclusion and Exclusion Criteria}

The selection criteria for MRgFUS CTT were as follows: 1) ET diagnosis confirmed by a senior neurologist, with postural and/or kinetic components reaching an intensity of at least $2-3 / 4 ; 2$ ) tremor resistance to pharmacological treatment, or appearance of side effects of drugs, preventing their use; 3) absence of dementia; and 4) strong disability related to tremor. Asymmetry of symptoms was not a selection criterion. No prefixed age limit was set. All patients were examined by a senior internist for medical contraindications. Antiaggregant therapy was stopped for 10 days before the intervention, and normal coagulation and blood pressure were checked in all patients prior to surgery.

\section{Clinical Scales and Subscales}

Primary endpoints were subjective tremor relief; Clinical Rating Scale for Tremor (CRST) with its parts A (scores 1-9), B (scores 10-14), and C (scores 15-21); ;1 activities of daily living (ADL) (scoring from 25 up to
100 maximum-higher scores corresponding to stronger impairment); and hand function (HF) subscores HF16 (items 11-14 of CRST, including spiral and line drawings and pouring for the treated hand [of 16 points]) and HF32 (items 11-14 for both hands). ${ }^{6,20}$ Secondary endpoints were the lesion size, the Montreal Cognitive Assessment (MoCA) score, the Hospital Anxiety and Depression Scale (HADS) score, ${ }^{44}$ and the World Health Organization Quality of Life Questionnaire (WHOQOL-BREF). ${ }^{41}$

\section{Histological Analysis}

A detailed localization analysis of the cerebellothalamic tract in the posterior subthalamic area was performed on the original histological sections, and maps were partly published in different versions of Morel's Stereotactic Atlas of the Human Thalamus and Basal Ganglia. ${ }^{16,31}$ Anatomical reappraisal of the interindividual variations of the cerebellothalamic tract normalized to the $\mathrm{mRN}$ in the axial stereotactic plane was conducted in order to provide maximal coverage of the tract without affecting surrounding neuroanatomical structures.

Histological sections and maps from 4 human brain hemispheres (Morel's cases Hb1, Hb3, Hb5, and Hb8) cut in their axial stereotactic plane were superimposed on the mRN. Figure 1 shows the superimposed brain hemispheres on the grid of Morel's case Hb1. Outlines of the cerebellothalamic tract were identified in the stereotactic space on the basis of myelin-stained sections and fitted onto Nissl drawn maps. The cerebellothalamic tract was always identified, as expected from previous works, in the space located between the RN and the subthalamic nucleus (STN) $3 \mathrm{~mm}$ below the intercommissural plane (ICP). However, it showed greater variability in its anteroposterior extension than previously thought. This led, in accordance with an approach already proposed for targeting the pallidothalamic tract in Parkinson disease (PD), ${ }^{17,18}$ to coverage of the maximal amount of the tract with 2 to 3 target lesion subunits. The target lesion subunits were deployed on the tract with the goal being to optimize target coverage and minimize risks for adjacent structures (i.e., mammillothalamic tract [mtt], STN, and somatosensory thalamus).

\section{Preoperative Target Preparation}

Pretargeting was performed on axial T2-weighted MR images cut in the stereotactic plane with either 2- or 3-mm thickness without gaps. The RN could always be identified and its center determined. The position of the 3 target lesion subunits was centered in the space between RN and STN, as described above. All targets were placed $3 \mathrm{~mm}$ below the ICP. Coordinates of the 3 target subunits were corrected in each case separately for mediolateral and anteroposterior dimensions.

\section{Procedure}

All interventions were performed using the ExAblate Neuro device (InSightec) in a 3-T MRI system (GE Discovery 750; GE Healthcare). Definitive targeting was determined on intraoperative axial T2-weighted images with the patient's head immobilized in the stereotactic frame and the transducer in place. Intraoperative axial 

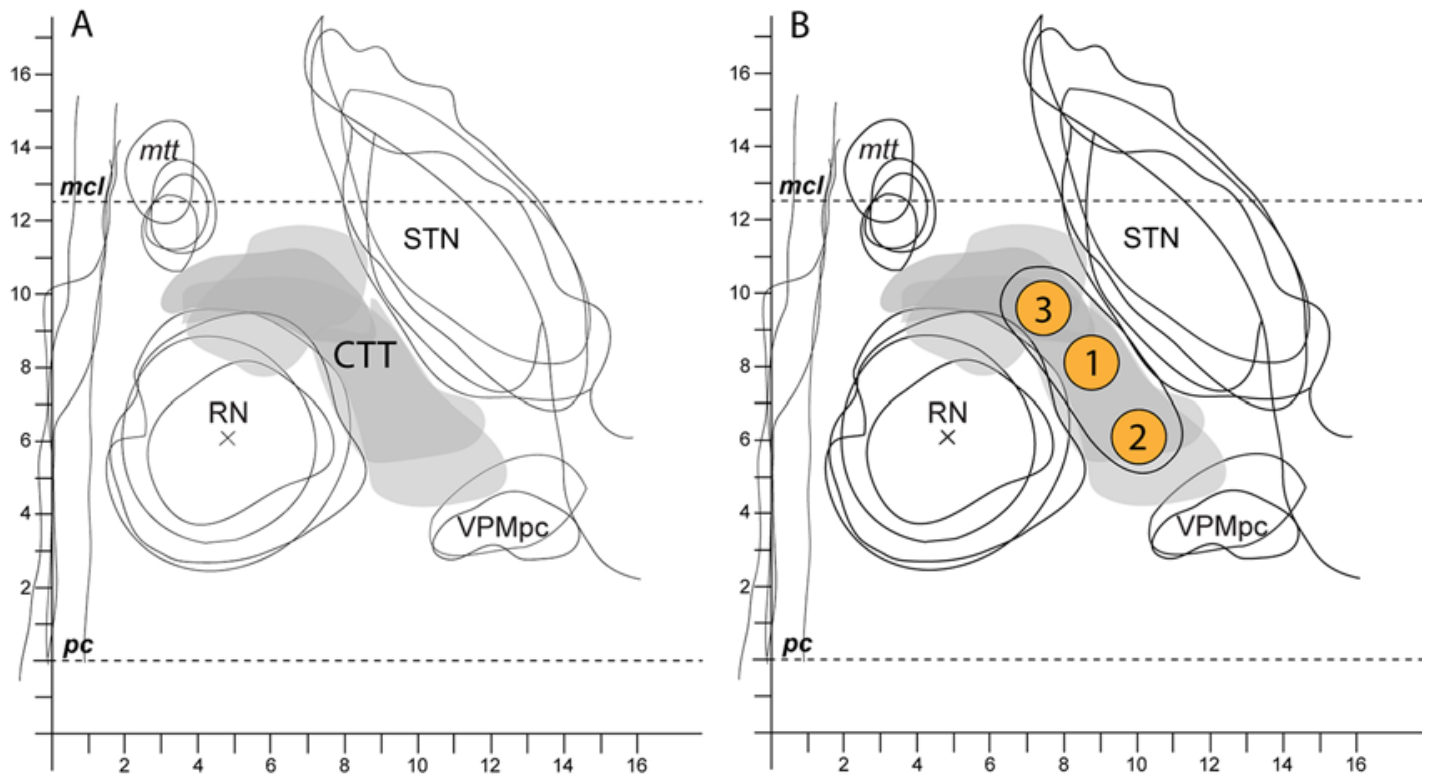

FIG. 1. Projections based on data from atlas maps of Morel's cases $\mathrm{Hb} 3, \mathrm{Hb} 5$, and $\mathrm{Hb} 8$ close to $3 \mathrm{~mm}$ below the ICP superimposed on the mRN, and from Gallay et al. (2008). The posterior commissure (pc) and midcommissural (mcl) distance correspond to case $\mathrm{Hb} 1$ (anterior commissure-posterior commissure distance of $25 \mathrm{~mm}$ ). The $\mathrm{mtt}, \mathrm{STN}$, and VPMpc are depicted. The outlines of the cerebellothalamic fibers for all 4 cases are shaded in gray. Target lesion subunits 1-3 in their proposed order of realization are depicted in orange. Target lesion subunit coordinates given from the $\mathrm{mRN}: 1$ (mRN $+4 \mathrm{~mm}$ laterally and $\mathrm{mRN}+2 \mathrm{~mm}$ anteriorly); 2 (mRN + 5-5.5 mm laterally and $\mathrm{mRN}$ ); and 3 ( $\mathrm{mRN}+2.5-3.0 \mathrm{~mm}$ laterally and $\mathrm{mRN}+3.5 \mathrm{~mm}$ anteriorly). Depicted dimensions of target subunits 1-3 correspond to the ultrasound focal region size. The numbered increments on the $\mathrm{x}$ and $\mathrm{y}$ axes represent millimeters. Figure is available in color online only.

T2-weighted images were cut with 3-mm thickness (no gap) and were of sufficient quality to be able to determine the mRN in every patient (example in Fig. 2). The natural transducer focal point was adjusted as close as possible to the center of the CTT target. The detailed procedure setup has been described previously. ${ }^{20,27}$ Final temperature sonications were applied to the different target lesion subunits according to their preplanned focal point coordinates. The order of sonications was, as seen in Fig. 1, from 1 to 3; target lesion subunit 1 is located in the middle of the space between the mtt and the ventral posterior medial nucleus, parvocellular division (VPMpc). Target lesion subunits 1-3 in their proposed order of realization are depicted in Fig. 1. Their coordinates are given in relation to the $\mathrm{mRN}$. Lesion subunit 1 is located $4 \mathrm{~mm}$ laterally to $\mathrm{mRN}, 2 \mathrm{~mm}$ anteriorly to $\mathrm{mRN}$, and $3 \mathrm{~mm}$ below the ICP. Lesion subunit 2 is located $5-5.5 \mathrm{~mm}$ laterally to $\mathrm{mRN}$, at the anteroposterior level of $\mathrm{mRN}$, and $3 \mathrm{~mm}$ below the ICP, and lesion subunit 3 is located $2.5-3.0 \mathrm{~mm}$ laterally, $3.5 \mathrm{~mm}$ anteriorly to $\mathrm{mRN}$, and $3 \mathrm{~mm}$ below the ICP.

Concerning the lesion volume of each target subunit, we consider a central area of ultrasound energy application of $1.5 \times 1.5 \times 3 \mathrm{~mm}$, representing the ultrasound focal region size as given by the manufacturer. Around it, further tissue lesioning will occur through heat diffusion. The goal was to obtain for each target lesion subunit a thermal dose of 240 cumulative equivalent minutes (CEM) at $43^{\circ} \mathrm{C}$ extending on a diameter of $2 \mathrm{~mm}$. Sonications were performed with the shortest possible duration and the corresponding power in order to provide the mentioned final thermal dose of 240 CEM, which represents a conservative value corresponding to a $100 \%$ probability of lesion. ${ }^{29,30}$ At 18 CEM there is a 50\% probability for thermal damage. ${ }^{29}$ According to the thermal doses achieved and if tremor suppression was already obtained (assessed based on spiral drawing, finger-nose test, and suppression of postural tremor) after lesion subunit 2 , subunit 3 could be left untouched.

Intraoperative images (e.g., Fig. 2) were obtained with the patient immobilized in the stereotactic frame, the transducer still in the treatment position, and the space between the transducer and scalp filled with degassed water. MR parameters of the intraoperative axial T2 sequences were as follows: pulse sequence FRFSE-XL, field of view 22.0, slice thickness $2.0 \mathrm{~mm}$, slice spacing $0.0 \mathrm{~mm}$, TE $100.5 \mathrm{msec}$, TR $3922.0 \mathrm{msec}$, echo train length 19, and bandwidth $31.2 \mathrm{kHz}$.

All patients received between 2 and 3 injections of methylprednisolone postoperatively. Dexamethasone $(6$ $\mathrm{mg} / \mathrm{day}$ ) was taken for 4 days after the procedure only, in order to avoid adrenal insufficiency after its discontinuation.

Target position reconstruction was performed for each patient on the basis of the MRI findings at day 2 after surgery as previously described, ${ }^{19,32,33}$ with a comparison between the desired target coordinates and the coordinates of the geometrical center of the lesions seen on sagittal and axial T2 images.

\section{Statistical Analysis}

Statistical analysis of quantitative scores compared with baseline was carried out using repeated ANOVA 

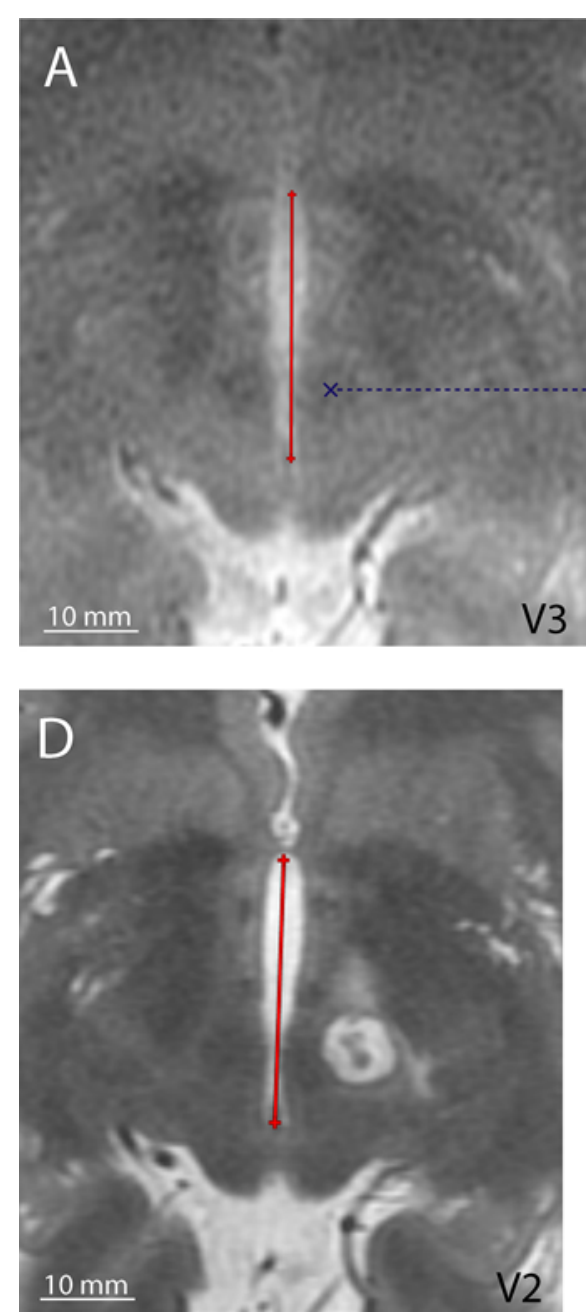
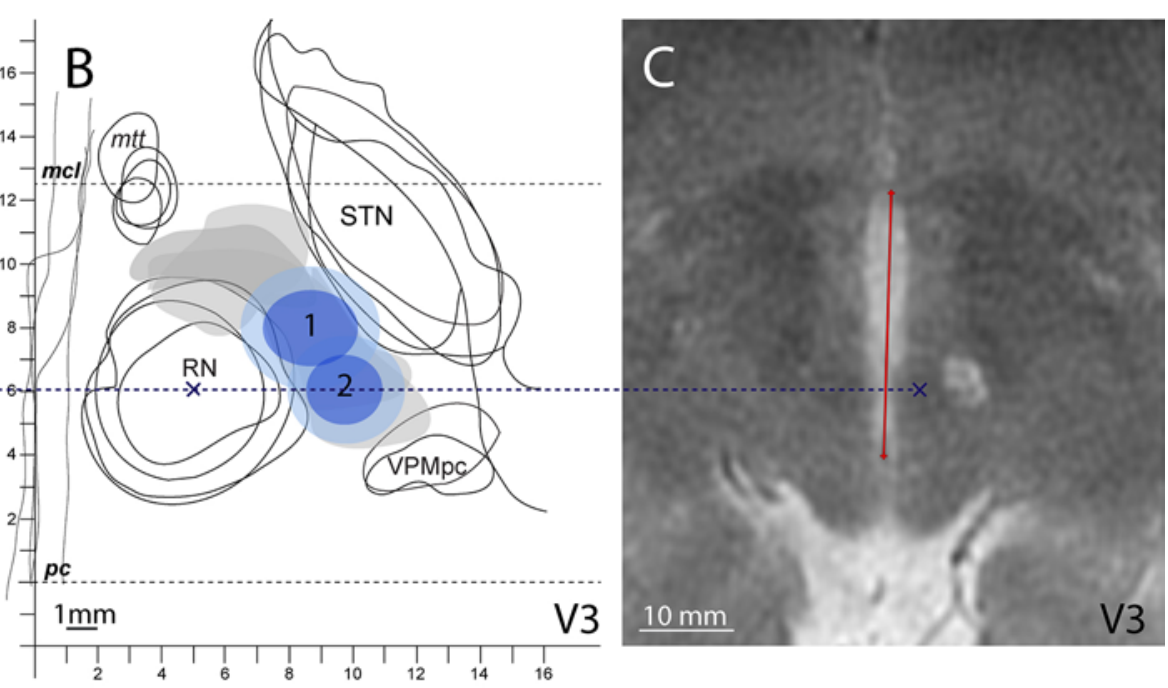

FIG. 2. A: Intraoperative axial MR T2 image $3 \mathrm{~mm}$ below the ICP (V3) (without head coil). B: Projections of the measured 18- and 240-CEM thermal doses, taking into account the submillimetric displacement of the realized target according to MR thermometry. Only 2 target lesion subunits were performed according to the protocol and the final absence of tremor either in posture or during spiral drawing. C: Axial T2 image at the end of the procedure, without head coil. D: MR axial T2 image at day 2 after the procedure, $2 \mathrm{~mm}$ below the ICP (V2), with the 32-channel head coil. The projected anterior commissure-posterior commissure line is depicted in red in panels A, C, and D. The map in panel B is based on data from the Morel atlas and from Gallay et al. (2008). Figure is available in color online only. measures and multiple comparisons were applied using a post hoc analysis with Bonferroni-Holm testing (Daniel's XL; https://www.xltoolbox.net/). Statistical significance was set at $\alpha<0.05$. Correlations were assessed with Pearson's coefficient, with agreement considered good for 0.5 $<\mathrm{r} \leq 0.75$ and excellent for $\mathrm{r}>0.75$. The mean values are given $\pm \mathrm{SD}$.

\section{Results}

Patients' characteristics are summarized in Table 1. Ten consecutive patients with chronic therapy-resistant ET were analyzed. All patients received unilateral CTT: in 8 for their most affected side, in 2 for their dominant side. Three patients benefited from an additional contralateral centrum medianum thalamotomy (CMT), and 1 patient received in addition to the CTT a bilateral central lateral thalamotomy (CLT) for therapy-resistant neurogenic pain. All patients were treated in a single session. One patient displayed concomitant PD, dominant on the side opposite to the treated one. The mean age at treatment was 66 \pm 8 years and the mean symptom duration was $31 \pm 14$ years. No patient was lost to follow-up. Due to distance, in 2 of 10 patients the 1-year postoperative control was performed through video and phone conversation. There was no bleeding or infection. All patients were discharged after a 1-night hospital stay.

The mean baseline CRST (of 144 points) was $48 \pm 12$ (n $=10)$; at 3 months it was $16 \pm 7(n=8, p<0.0001)$, corresponding to a $66 \%$ reduction of the mean; and it was $17 \pm$ $8(\mathrm{n}=8, \mathrm{p}<0.0001)$ at 1 year $(64 \%$ reduction of the mean). The mean patient-rated tremor relief after 2 days was $95 \%$ $(\mathrm{n}=10$, median $100 \%)$; $96 \%$ at 3 months $(\mathrm{n}=10$, median $100 \%)$; and $93 \%$ at 1 year $(\mathrm{n}=10$, median $96 \%)$.

The mean HF16 was $11.0 \pm 2.1$ at baseline, $0.7 \pm 0.7(\mathrm{p}$ $<0.0001)$ at 3 months, and $0.8 \pm 0.9$ at 1 year $(\mathrm{n}=10, \mathrm{p}<$ $0.0001,93 \%$ mean reduction). The minimum reduction for the HF16 at 1 year was $78 \%$. The mean HF32 was $20.4 \pm$ 4.3 at baseline, $9.4 \pm 4.1$ at 3 months $(p=0.0001)$, and 9.0 \pm 3.3 at 1 year $(n=10, p<0.0001,56 \%$ mean reduction $)$ (see Fig. 3). Evolution of the mean CRST parts A, B, and $\mathrm{C}$ is shown in Fig. 4. The mean baseline CRST was 11.8 \pm 3.9 for part $\mathrm{A}, 22.1 \pm 5.2$ for part $\mathrm{B}$, and $14.2 \pm 3.4$ for part C. After 3 months the CRST scores were $3.6 \pm 1.5$ for part $A(p=0.0001,69 \%$ reduction $) ; 9.9 \pm 4.4$ for part $\mathrm{B}(\mathrm{p}=0.0001,54 \%$ reduction); and $2.6 \pm 2.0$ for part $\mathrm{C}$ ( $\mathrm{p}<0.0001,82 \%$ reduction). At 1 year they were $4.3 \pm$ $1.9(\mathrm{n}=8, \mathrm{p}<0.001,66 \%$ reduction) for part $\mathrm{A} ; 9.5 \pm 3.9$ $(\mathrm{p}=0.0001,58 \%$ reduction) for part $\mathrm{B}$; and $3.4 \pm 2.6(\mathrm{p}=$ $0.0001,77 \%$ reduction) for part $\mathrm{C}$. 
TABLE 1. Characteristics in 10 patients with chronic therapy-resistant ET

\begin{tabular}{lc}
\hline \multicolumn{1}{c}{ Characteristic } & Value \\
\hline No. of consecutive patients & 10 \\
\hline No. $w /$ CTT (rt/lt) & $10(4 / 6)$ \\
\hline Most affected side/dominant side & $8 / 2$ \\
\hline$\%$ female & $20 \%$ \\
\hline Mean age at treatment, yrs & $66 \pm 8$ \\
\hline Mean symptom duration, yrs & $31 \pm 14$ \\
\hline Mean CRST score (of 144 points) & $48 \pm 12$ \\
\hline Baseline & $16 \pm 7, p<0.0001,-66 \%$ \\
\hline At 3 mos follow-up & $17 \pm 8, p<0.0001,-64 \%$ \\
\hline At 1 yr follow-up & $95 \%$, median $100 \%$ \\
\hline Mean global tremor relief (operated side) & $96 \%$, median $100 \%$ \\
\hline After 2 days & $93 \%$, median $96 \%$ \\
\hline At 3 mos follow-up & \\
\hline At 1 yr follow-up & $54 \pm 11$ \\
\hline Mean ADL score & $37 \pm 8, p<0.003$ \\
\hline Preop ( $n=10)$ & $37 \pm 9, p<0.003$ \\
\hline At 3 mos follow-up $(n=8)$ & \\
\hline At 1 yr follow-up $(n=10)$ &
\end{tabular}

Unless otherwise indicated, values are expressed as the mean \pm SD.

The difficulties regarding the ADL were reduced from a mean score of $54 \pm 11$ at baseline to $37 \pm 9(n=10$, p < $0.003)$ at 1 year, corresponding to a $51 \%$ reduction of the mean.

\section{Secondary Outcome Measures}

The baseline mean MoCA score $(\mathrm{n}=10)$ was $29.1 \pm 0.7$; after 2 days it was $29.2 \pm 1.2(\mathrm{n}=10)$, and it was $29.3 \pm 0.7$ at 1 year $(\mathrm{n}=7)$. The mean HADS score was $11.4 \pm 5.6$ preoperatively and $7.7 \pm 3.2$ at 1 year $(n=10, p=0.1)$, and the mean WHOQOL-BREF score was $97 \pm 7$ at baseline and $104 \pm 10$ at 1 year $(\mathrm{p}=0.12)$.

Sonication duration applied to reach maximal temperatures was between 9 and 33 seconds, and the mean sonication power was $1000 \mathrm{~W}$ (range 650-1400 W). The mean maximal energy necessary for reaching final temperatures was $13,720 \mathrm{~J}$ (range 5850-36,000 J). The mean skull density ratio as measured by the ExAblate Neuro (version 7.0) was $0.54 \pm 0.06$ (range 0.33-0.62) (Supplemental Table 1).

The mean volume of CTT targets measured 2 days after surgery was $172 \pm 63 \mathrm{~mm}^{3}$ (range $55-280 \mathrm{~mm}^{3}$ ) on T2-weighted MR images and $146 \pm 70 \mathrm{~mm}^{3}$ (range 35-252 $\mathrm{mm}^{3}$ ) on susceptibility weighted angiography (SWAN). The mean dorsoventral size of the lesions, all centered at $3 \mathrm{~mm}$ below the ICP, was $6.6 \pm 1.1 \mathrm{~mm}$ on MR T2 at 2 days (range 4.4-7.7 mm). Applied mean thermal dose volumes in the target were $101 \pm 48 \mathrm{~mm}^{3}$ (range 44-224 $\mathrm{mm}^{3}$ ) for $18 \mathrm{CEM}$ and $18 \pm 12 \mathrm{~mm}^{3}$ (range $2-38 \mathrm{~mm}^{3}$ ) for 240 CEM. Intraoperative axial T2 and postoperative (2 days) axial T2 mean lesion surfaces were compared with their 18-CEM and 240-CEM corresponding mean thermal doses and were plotted in Fig. 5.

Pearson's analysis showed excellent correlations between 18-CEM and 240-CEM thermal doses $(r=0.79)$; between 18-CEM thermal dose surfaces and intraoperative axial MR T2 lesion surfaces $(r=0.77)$; and between axial MR T2 surfaces 2 days after the procedure and 18CEM thermal doses $(r=0.8), 240$-CEM thermal doses $(r=$ 0.76 ), and intraoperative axial $\mathrm{T} 2$ surfaces $(\mathrm{r}=0.83$ ) (Fig. 6 ). The measured MR T2 volumes of lesions at 2 days showed good correlations with the extrapolated 18-CEM $(r=0.69)$ and 240-CEM $(r=0.64)$ thermal dose volumes.

\section{Side Effects}

Sonications were painful for a few seconds in 4 patients. One patient had a frontal scalp swelling lasting a few days. Gait difficulties-only detectable on tandem gait-were present in 2 patients after 2 days; in one of
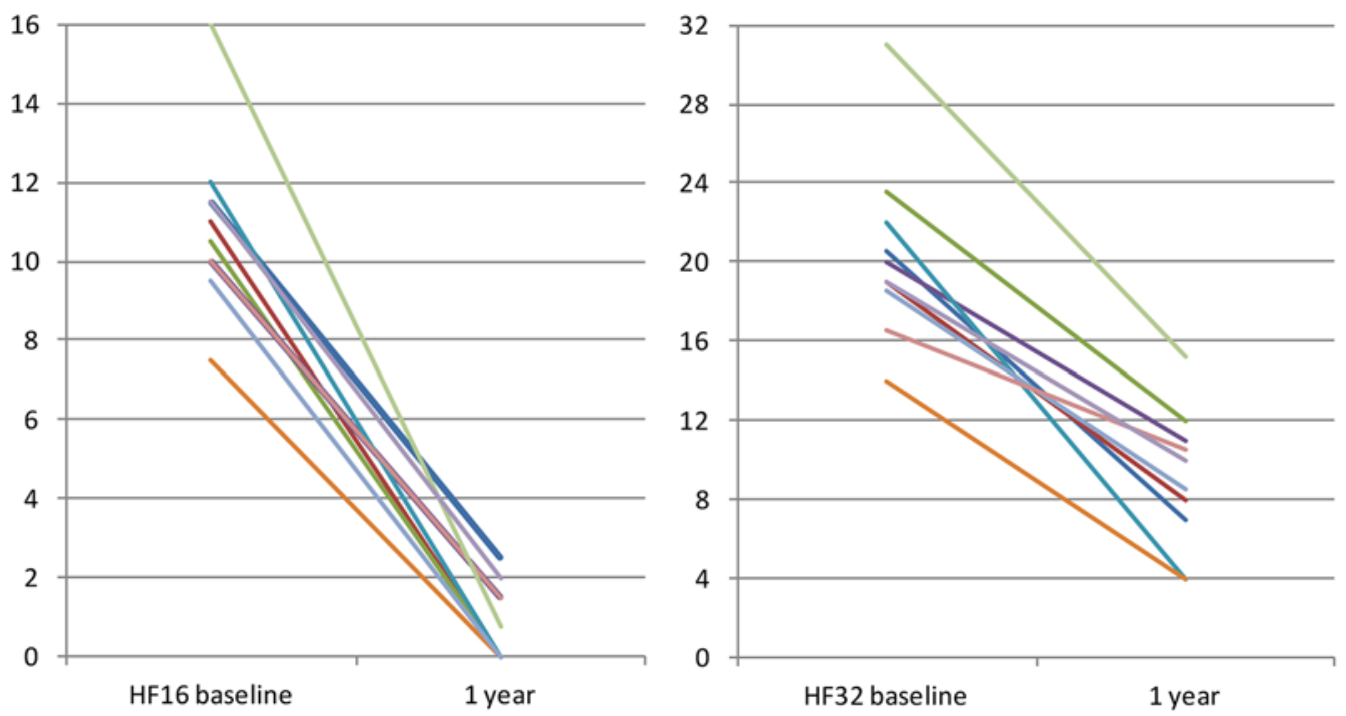

FIG. 3. HF scores (HF16 for the treated hand, HF32 for both hands) after CTT in all 10 patients at baseline and 1 year postoperatively. Figure is available in color online only. 


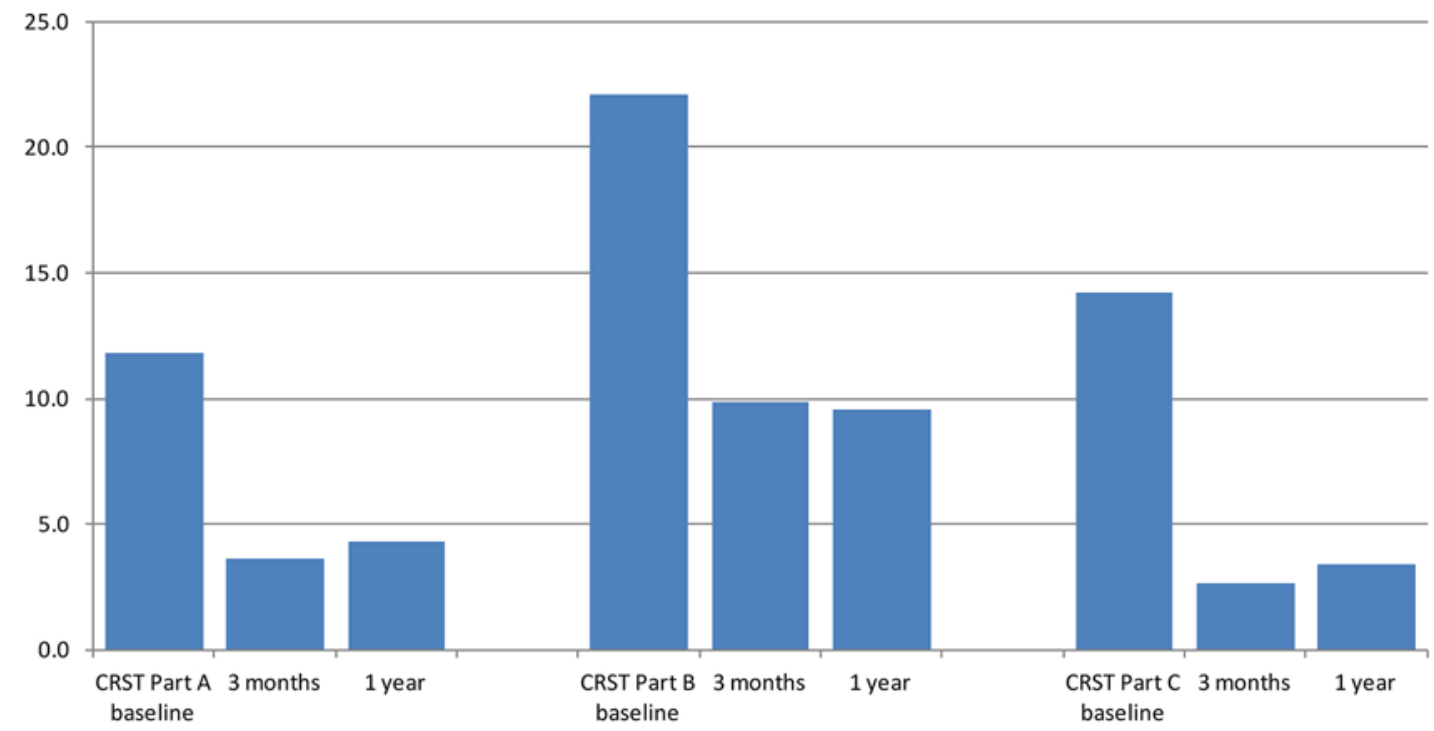

FIG. 4. Histograms showing the evolution of CRST subscores A, B, and C, from baseline to 3 months and 1 year after CTT. Figure is available in color online only.

them the gait difficulties were increased in comparison to preoperatively, and in the other they were new. At 1 year, 3 patients had more difficulties on the tandem gait than preoperatively. Of those 3 patients, 1 had a polyneuropathy and 1 had a concomitant PD. In contrast, 2 patients had an improvement of their tandem gait in comparison with baseline. Subjective gait difficulties without detected status anomaly were present in 5 patients at 2 days, and in 2 at 1 year. Five patients complained about slight speech difficulties at 2 days, whereas at 3 months and 1 year only 1 patient (with concomitant PD) complained about them. There was no dysarthria, dysphonia, or hypophonia. The patient in case 2 experienced paresthesias on the face and left hand after his CMT lesion from the 1st postoperative day onward, which was still persistent after 1 year.

\section{Discussion}

This prospective case series of 10 consecutive interventions for ET is placed in the context of an 8-year experience with the MRgFUS CTT for treatment of ET. Partial symptom control in some cases ${ }^{20}$ led us to revise our targeting strategy in order to optimize target coverage through a histological reappraisal of the interindividual variability of the cerebellothalamic tract as well as the use of preplanned focal point displacements, shortest sonication duration, and thermal dose control. This effort was
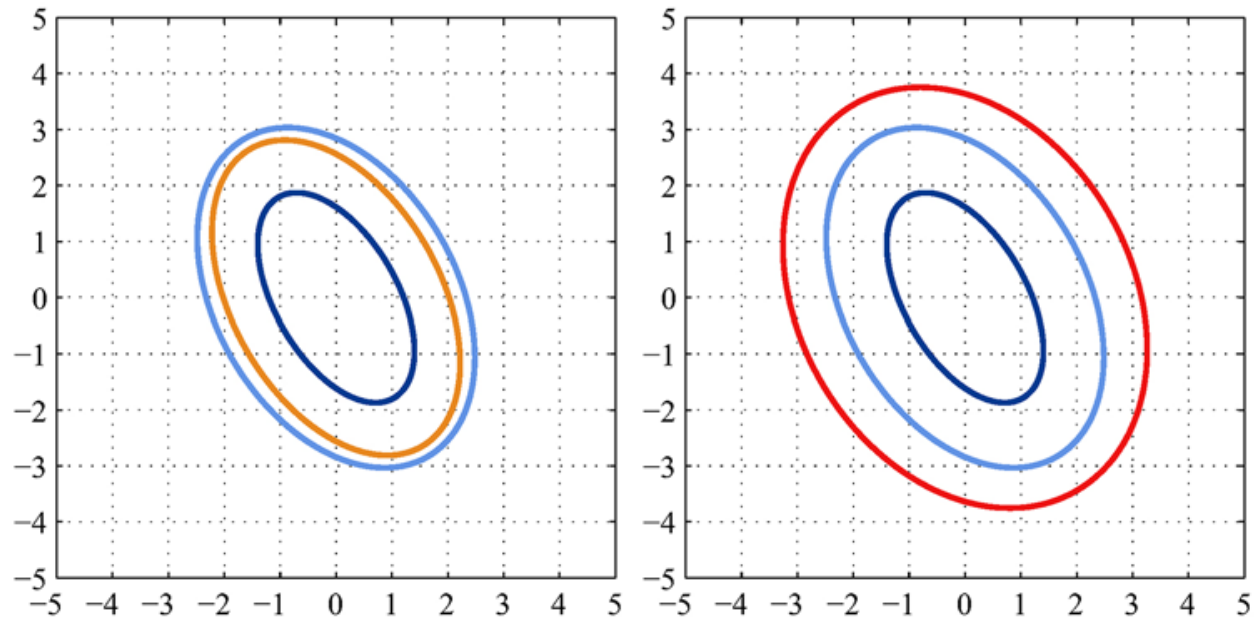

FIG. 5. Plots of 18-CEM thermal doses in light blue (mean diameters $6.6 \pm 1.1 \mathrm{~mm}$ and $4.3 \pm 0.7 \mathrm{~mm}), 240$-CEM thermal doses in dark blue (mean diameters $4.1 \pm 1.4 \mathrm{~mm}$ and $2.2 \pm 0.6 \mathrm{~mm}$ ), intraoperative axial MR T2 in orange (mean diameters $6.1 \pm 1.2 \mathrm{~mm}$ and $3.7 \pm 0.4 \mathrm{~mm}$ ), and 2-day axial MR T2 in red (mean diameters $8.0 \pm 1.0 \mathrm{~mm}$ and $6.0 \pm 1.1 \mathrm{~mm}$ ). Figure is available in color online only. 

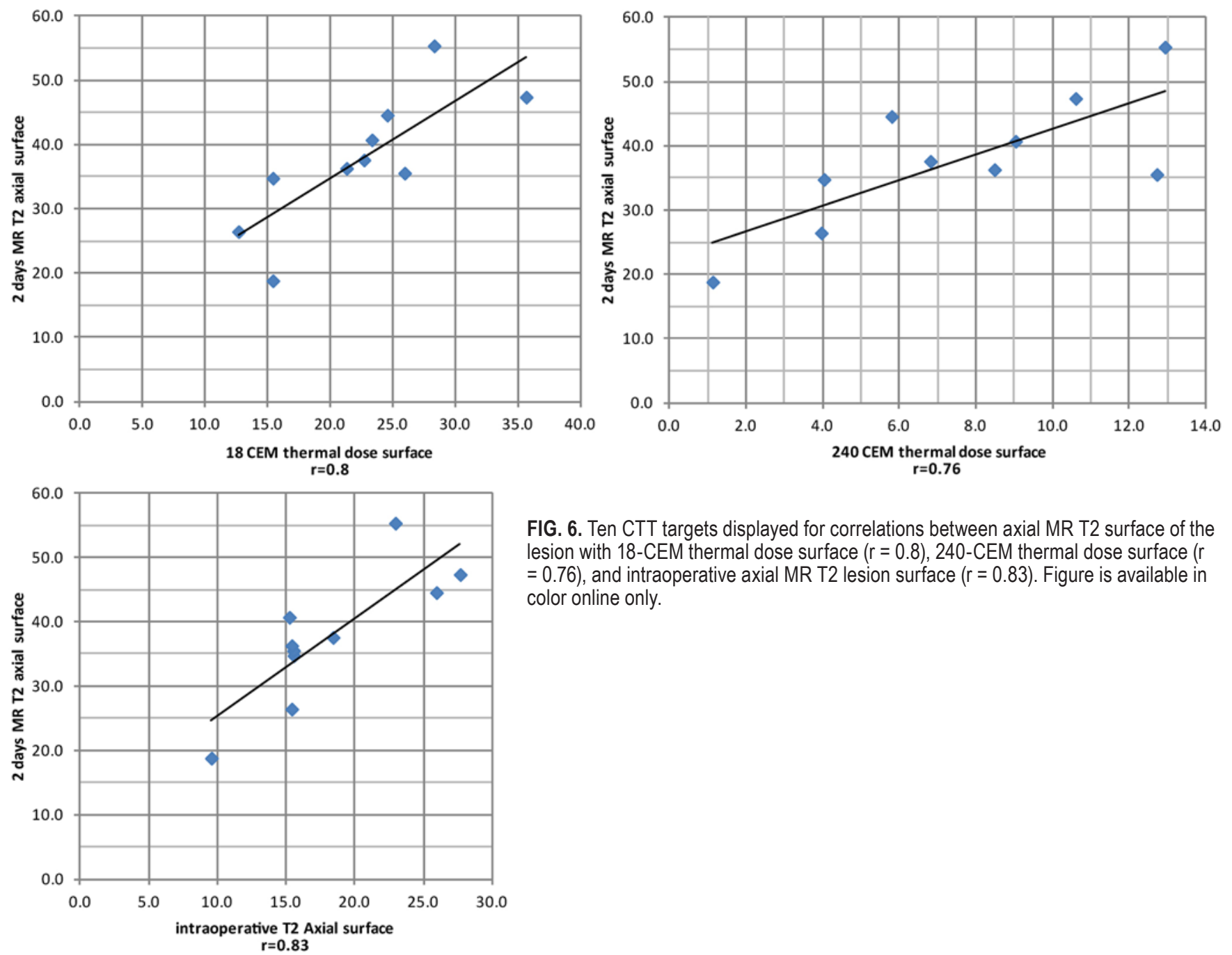

FIG. 6. Ten CTT targets displayed for correlations between axial MR T2 surface of the lesion with 18-CEM thermal dose surface $(r=0.8), 240$-CEM thermal dose surface $(r$ $=0.76)$, and intraoperative axial MR T2 lesion surface $(r=0.83)$. Figure is available in color online only.

undertaken following the reappraisal of the pallidothalamic target in PD. ${ }^{17,18}$

\section{Analysis of the Clinical Results}

There was no bias in favor of cases with asymmetrical tremor, as shown by the baseline HF16 $(11 \pm 2)$ and HF32 $(20 \pm 4)$ subscores.

In comparison to our previously published series, ${ }^{20}$ baseline CRST scores were slightly lower. This observation, in spite of the modest number of cases in this series, may suggest an evolution in terms of referrals, now including also patients with moderate to strong tremors, as trust in the technique gradually grows in the neurological community. In our previous study, 33\% of the patients were classified in group 1 with the most severe tremor forms (HF32 > 28/32). Only 1 patient $(10 \%)$ in the current study qualified for this group, not allowing us to perform conclusive comparisons with our aforementioned series.

Patients reported a mean $96 \%$ tremor relief for the treated side at 3 months and $93 \%$ at 1 year after the treatment. This fit in with the $94 \%$ mean reduction for the HF16 at 3 months and $92 \%$ at 1 year postoperatively, which are ob- jective measurements of tremor. There was a $51 \%$ mean improvement for the ADL scores at 3 months and 1 year equally.

According to the relative symmetry of symptoms, the $66 \%$ reduction for the mean CRST score at 3 months and $64 \%$ reduction at 1 year were mostly due to the impact of unilateral treatment on part C of the CRST score $(82 \%$ reduction at 3 months and $77 \%$ reduction at 1 year). The adjunction to CTT of a contralateral CMT in 3 patients and of a bilateral CLT certainly played a role, as shown by the HF32 score reductions of $56 \%$ at 1 year. Some tremor reduction was indeed found after CMT and CLT in 3 of 4 patients, although it was more modest than after CTT (see Fig. 7 and Supplemental Fig. 1). There is current interest in $\mathrm{CMT}^{1,25}$ for the treatment of movement disorders. It is being explored in our center as a secondary target to CTT for bilateral tremor interventions. To our surprise, the bilateral CLT, performed in addition to CTT in one of our patients who was suffering significantly from both ET and neurogenic pain (after posttraumatic myelopathy), provided a subtotal tremor control on the side contralateral to the one treated by CTT. 

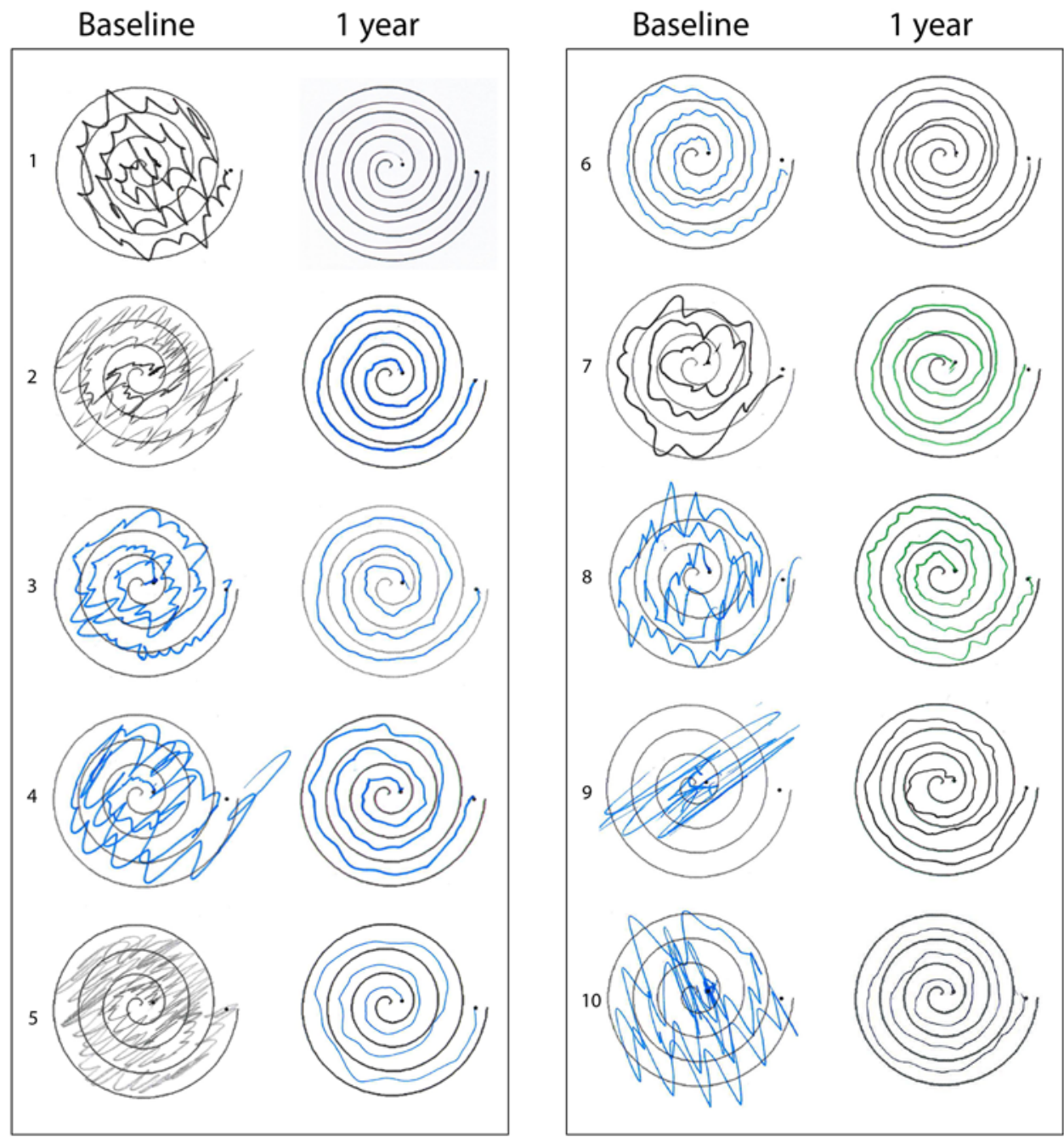

FIG. 7. Spirals drawn at baseline and at the 1 -year follow-up by 10 consecutive patients treated with CTT. Figure is available in color online only.

At the level of CRST, HF16, ADL, and tremor relief scores there was a stability of improvements between 3 months and 1 year, with this speaking against future tremor recurrences.

\section{MRI and Thermal Doses}

As discussed recently, ${ }^{18} \mathrm{CEM}$ thresholds used in this analysis are based on data obtained in animal experiments, with $240 \mathrm{CEM}$ as the value corresponding to $100 \%$ and 18 CEM for $50 \%$ probability of thermal damage in the tissue..$^{28}$ The size of the final lesion will accordingly lie somewhere between the 240 and 18 CEM thermal dose surfaces, depending on additional factors not entirely elucidated yet (white/gray matter and vascular changes with age, among others). The measured lesions intra- and postoperatively on MR images showed a similar pattern to that already published for the pallidothalamic tract in PD. MR T2 images obtained at the end of the procedure showed lesions slightly smaller than those at their 18-CEM thermal dose. At 2 days, the MR T2 lesions were bigger than those at the 18-CEM thermal doses, due to the develop- ment of intralesional cytotoxic edema. Correlation analysis showed high predictability for postoperative MR T2 lesion sizes, given the intraoperative axial MR T2 lesion size $(r=0.83)$, as well as the 240-CEM $(r=0.76)$ and 18CEM $(r=0.8)$ thermal dose surfaces. As shown in recent studies, there is a growing interest in thermal dose-based approaches. ${ }^{12,23}$

\section{Targeting and Image Quality}

The cerebellothalamic tract has a much more straightforward anatomical course than the pallidothalamic tract in the subthalamic region. Despite this fact, we still cannot rely on diffusion MR tractography of this region for direct lesioning purposes due to relatively poor radiological accuracy. ${ }^{7,36}$ In this context, we still favor an atlas-based histological approach, taking interindividual variability into account. Targeting the cerebellothalamic tract by using an approach based on visualization of the $\mathrm{RN}$ relies on intraoperative imaging of sufficient resolution. As illustrated in Fig. 2, the $\mathrm{mRN}$ could be determined in all patients at 3 $\mathrm{mm}$ below the ICP. 


\section{Efficiency, Safety, and Side Effects}

There was no bleeding and no infection. Sonications were painful in 4 patients, but they only lasted a few seconds and no patient suffered a headache lasting more than a few hours after removal of the head fixation frame. One patient with concomitant PD suffered from paresthesias in the face and hand region on the side contralateral to his CMT lesion from the 1st postoperative day, which had not completely recovered after 1 year. This was due to an extension of the thermal lesion into the ventral posterior complex.

The occurrence of subjective slight speech difficulties was high 2 days after CTT (5 patients) but subsided within weeks and persisted only in 1 patient with concomitant PD. Complaints concerning gait were also initially frequent (5 patients). However, an objective worsening of gait was detected only in 2 patients and only on the tandem gait. At 1-year follow-up, tandem gait was worsened in 3 patients compared to baseline. Of those 3 patients, 1 had a polyneuropathy and 1 had a concomitant PD.

Our current working hypothesis to explain the observed gait difficulties addresses a temporary slowing down of leg motricity and/or a reduction in muscle tone on the treated side, which will be noticed particularly when proximal and axial muscles are involved (e.g., in tandem gait). We propose a similar explanation for the mentioned speech difficulties, which did not imply a dysarthria. The presence of reduced preoperative thalamocortical and cerebellar reserve ${ }^{19}$ may well underlie these manifestations.

There was no change in MoCA testing results, nor were there any complaints about cognitive difficulties during the whole follow-up of 1 year.

The safety and accuracy profile of the MRgFUS technique has been repeatedly scrutinized in recent years. ${ }^{13,19,33}$ The actual challenge rests nowadays in proper target heat coverage. Thalamotomy of the VLp (Vim) by either radiofrequency lesioning or Gamma Knife surgery has shown efficacy and stability over time..$^{2,24,38,42,45}$ The first MRgFUS large series ${ }^{9}$ (double-blinded, sham-controlled) have not so far been able to replicate the rates of tremor control obtained by radiofrequency lesioning, deep brain stimulation, ${ }^{34}$ and Gamma Knife surgery. Despite the small number of patients in this case series, the consistency of tremor relief over the whole consecutive group (at 1 year the HF16 reduction range was 78\%-100\%, mean 93\%) allows reasonably safe preliminary conclusions concerning the efficacy of MRgFUS CTT. This consistency of tremor relief compares very favorably with the recent results of Gallay et al..$^{20}$ (HF16 reduction range $0 \%-100 \%$ ).

\section{Conclusions}

Our results suggest that MRgFUS CTT is a very effective treatment option for chronic therapy-resistant ET. Technical adaptations and histological reappraisal have allowed us to achieve consistently high tremor relief (> 90\%) in a consecutive series of 10 patients.

\section{Acknowledgments}

We thank Mrs. Franziska Rossi for coordination and administrative organization; Mrs. Tanja Thalmann for intraopera- tive patient support and monitoring; Drs. Milek Kowalski and Alexander Arnold for internal medicine evaluations; Drs. Anouk Magara, Maja Strasser, and Robert Bühler for neurological evaluations; Drs. Payam Pourtehrani, Oskar Blosser, and Mike Fitze as well as their colleagues of Rodiag Diagnostic Centers for CT and MR imaging (Roxanne Jeanmonod and Philippe Ogay) for physical therapy support, and also Samuel Ryser for intraoperative patient care.

\section{References}

1. Adams JE, Rutkin BB: Lesions of the centrum medianum in the treatment of movement disorders. Confin Neurol 26:231245,1965

2. Akbostanci MC, Slavin KV, Burchiel KJ: Stereotactic ventral intermedial thalamotomy for the treatment of essential tremor: results of a series of 37 patients. Stereotact Funct Neurosurg 72:174-177, 1999

3. Bain PG, Findley LJ, Atchison P, Behari M, Vidailhet M, Gresty M, et al: Assessing tremor severity. J Neurol Neurosurg Psychiatry 56:868-873, 1993

4. Bertrand C, Hardy J, Molina-Negro P, Martínez SN: Optimum physiological target for the arrest of tremor, in Third Symposium on Parkinson's Disease. Edinburgh: Livingstone, 1969, pp 251-259

5. Bertrand C, Hardy J, Molina-Negro P, Martinez SN: Tremor of attitude. Confin Neurol 31:37-41, 1969

6. Blomstedt P, Sandvik U, Hariz MI, Fytagoridis A, Forsgren L, Hariz GM, et al: Influence of age, gender and severity of tremor on outcome after thalamic and subthalamic DBS for essential tremor. Parkinsonism Relat Disord 17:617-620, 2011

7. Calabrese E: Diffusion tractography in deep brain stimulation surgery: a review. Front Neuroanat 10:45, 2016

8. Chang JW, Park CK, Lipsman N, Schwartz ML, Ghanouni $\mathrm{P}$, Henderson JM, et al: A prospective trial of magnetic resonance-guided focused ultrasound thalamotomy for essential tremor: results at the 2-year follow-up. Ann Neurol 83:107-114, 2018

9. Elias WJ, Huss D, Voss T, Loomba J, Khaled M, Zadicario E, et al: A pilot study of focused ultrasound thalamotomy for essential tremor. N Engl J Med 369:640-648, 2013

10. Elias WJ, Lipsman N, Ondo WG, Ghanouni P, Kim YG, Lee $\mathrm{W}$, et al: A randomized trial of focused ultrasound thalamotomy for essential tremor. N Engl J Med 375:730-739, 2016

11. Fahn S, Tolosa E, Marín C: Clinical Rating Scale for Tremor, in Jankovic J, Tolosa E (eds): Parkinson's Disease and Movement Disorders, ed 2. Baltimore: Williams \& Wilkins, 1993, pp 271-280

12. Federau C, Goubran M, Rosenberg J, Henderson J, Halpern $\mathrm{CH}$, Santini V, et al: Transcranial MRI-guided high-intensity focused ultrasound for treatment of essential tremor: a pilot study on the correlation between lesion size, lesion location, thermal dose, and clinical outcome. J Magn Reson Imaging 48:58-65, 2018

13. Fishman PS, Elias WJ, Ghanouni P, Gwinn R, Lipsman N, Schwartz M, et al: Neurological adverse event profile of magnetic resonance imaging-guided focused ultrasound thalamotomy for essential tremor. Mov Disord 33:843-847, 2018

14. Forel A: Untersuchungen über die Haubenregion und ihre oberen Verknüpfungen im Gehirne des Menschen und einiger Säugethiere, mit Beiträgen zu den Methoden der Gehirnuntersuchung. Arch Psychiatr Nervenkr 7:393-495, 1877

15. Fytagoridis A, Sandvik U, Aström M, Bergenheim T, Blomstedt P: Long term follow-up of deep brain stimulation of the caudal zona incerta for essential tremor. J Neurol Neurosurg Psychiatry 83:258-262, 2012

16. Gallay MN, Jeanmonod D, Liu J, Morel A: Human pallidothalamic and cerebellothalamic tracts: anatomical basis for 
functional stereotactic neurosurgery. Brain Struct Funct 212:443-463, 2008

17. Gallay MN, Moser D, Federau C, Jeanmonod D: Anatomical and technical reappraisal of the pallidothalamic tractotomy with the incisionless transcranial MR-guided focused ultrasound. A technical note. Front Surg 6:2, 2019

18. Gallay MN, Moser D, Federau C, Jeanmonod D: Radiological and thermal dose correlations in pallidothalamic tractotomy with MRgFUS. Front Surg 6:28, 2019

19. Gallay MN, Moser D, Jeanmonod D: Safety and accuracy of incisionless transcranial MR-guided focused ultrasound functional neurosurgery: single-center experience with 253 targets in 180 treatments. J Neurosurg 130:1234-1243, 2019

20. Gallay MN, Moser D, Rossi F, Pourtehrani P, Magara AE, Kowalski M, et al: Incisionless transcranial MR-guided focused ultrasound in essential tremor: cerebellothalamic tractotomy. J Ther Ultrasound 4:5, 2016

21. Hassler R: Architectonic organization of the thalamic nuclei, in Schaltenbrand G, Walker AE (eds): Stereotaxy of the Human Brain. Anatomical, Physiological, and Clinical Applications, ed 2. Stuttgart: Thieme, 1982, pp 140-180

22. Ito Z: Stimulation and destruction of the prelemniscal radiation or its adjacent area in various extrapyramidal disorders. Confin Neurol 37:41-48, 1975

23. Jones RM, Kamps S, Huang Y, Scantlebury N, Lipsman N, Schwartz ML, et al: Accumulated thermal dose in MRI-guided focused ultrasound for essential tremor: repeated sonications with low focal temperatures. J Neurosurg [epub ahead of print May 10, 2019. DOI: 10.3171/2019.2.JNS182995]

24. Kondziolka D, Ong JG, Lee JYK, Moore RY, Flickinger JC, Lunsford LD: Gamma Knife thalamotomy for essential tremor. J Neurosurg 108:111-117, 2008

25. Krauss JK, Pohle T, Weigel R, Burgunder JM: Deep brain stimulation of the centre median-parafascicular complex in patients with movement disorders. J Neurol Neurosurg Psychiatry 72:546-548, 2002

26. Ledermann K, Jeanmonod D, McAleese S, Aufenberg C, Opwis K, Martin-Soelch C: Effects of cerebellothalamic tractotomy on cognitive and emotional functioning in essential tremor: a preliminary study in 5 essential tremor patients. Stereotact Funct Neurosurg 93:127-132, 2015

27. Magara A, Bühler R, Moser D, Kowalski M, Pourtehrani P, Jeanmonod D: First experience with MR-guided focused ultrasound in the treatment of Parkinson's disease. J Ther Ultrasound 2:11, 2014

28. Magnin M, Jetzer U, Morel A, Jeanmonod D: Microelectrode recording and macrostimulation in thalamic and subthalamic MRI guided stereotactic surgery. Neurophysiol Clin 31:230-238, 2001

29. McDannold N, Livingstone M, Top CB, Sutton J, Todd N, Vykhodtseva N: Preclinical evaluation of a low-frequency transcranial MRI-guided focused ultrasound system in a primate model. Phys Med Biol 61:7664-7687, 2016

30. Meshorer A, Prionas SD, Fajardo LF, Meyer JL, Hahn GM, Martinez AA: The effects of hyperthermia on normal mesenchymal tissues. Application of a histologic grading system. Arch Pathol Lab Med 107:328-334, 1983

31. Morel A: Stereotactic Atlas of the Human Thalamus and Basal Ganglia. New York: CRC Press, 2007

32. Moser D, Zadicario E, Schiff G, Jeanmonod D: Measurement of targeting accuracy in focused ultrasound functional neurosurgery. Neurosurg Focus 32(1):E2, 2012

33. Moser D, Zadicario E, Schiff G, Jeanmonod D: MR-guided focused ultrasound technique in functional neurosurgery: targeting accuracy. J Ther Ultrasound 1:3, 2013

34. Pahwa R, Lyons KE, Wilkinson SB, Simpson RK Jr, Ondo WG, Tarsy D, et al: Long-term evaluation of deep brain stimulation of the thalamus. J Neurosurg 104:506-512, 2006

35. Park YS, Jung NY, Na YC, Chang JW: Four-year follow-up results of magnetic resonance-guided focused ultrasound thalamotomy for essential tremor. Mov Disord 34:727-734, 2019

36. Petersen MV, Lund TE, Sunde N, Frandsen J, Rosendal F, Juul N, et al: Probabilistic versus deterministic tractography for delineation of the cortico-subthalamic hyperdirect pathway in patients with Parkinson disease selected for deep brain stimulation. J Neurosurg 126:1657-1668, 2017

37. Schreglmann SR, Bauer R, Hägele-Link S, Bhatia KP, Natchev P, Wegener N, et al: Unilateral cerebellothalamic tract ablation in essential tremor by MRI-guided focused ultrasound. Neurology 88:1329-1333, 2017

38. Schuurman PR, Bosch DA, Bossuyt PM, Bonsel GJ, van Someren EJ, de Bie RM, et al: A comparison of continuous thalamic stimulation and thalamotomy for suppression of severe tremor. N Engl J Med 342:461-468, 2000

39. Sinai A, Nassar M, Eran A, Constantinescu M, Zaaroor M, Sprecher E, et al: Magnetic resonance-guided focused ultrasound thalamotomy for essential tremor: a 5-year singlecenter experience. J Neurosurg [epub ahead of print July 5, 2019. DOI: 10.3171/2019.3.JNS19466]

40. Spiegel EA, Wycis HT, Szekely EG, Adams DJ, Flanagan M, Baird HW III: Campotomy in various extrapyramidal disorders. J Neurosurg 20:871-884, 1963

41. The WHOQOL Group: Development of the World Health Organization WHOQOL-BREF quality of life assessment. Psychol Med 28:551-558, 1998

42. Young RF, Li F, Vermeulen S, Meier R: Gamma Knife thalamotomy for treatment of essential tremor: long-term results. J Neurosurg 112:1311-1317, 2010

43. Zaaroor M, Sinai A, Goldsher D, Eran A, Nassar M, Schlesinger I: Magnetic resonance-guided focused ultrasound thalamotomy for tremor: a report of 30 Parkinson's disease and essential tremor cases. J Neurosurg 128:202-210, 2018

44. Zigmond AS, Snaith RP: The Hospital Anxiety and Depression Scale. Acta Psychiatr Scand 67:361-370, 1983

45. Zirh A, Reich SG, Dougherty PM, Lenz FA: Stereotactic thalamotomy in the treatment of essential tremor of the upper extremity: reassessment including a blinded measure of outcome. J Neurol Neurosurg Psychiatry 66:772-775, 1999

\section{Disclosures}

The authors report no conflict of interest concerning the materials or methods used in this study or the findings specified in this paper.

\section{Author Contributions}

Conception and design: Gallay, Jeanmonod. Acquisition of data: all authors. Analysis and interpretation of data: Gallay. Drafting the article: Gallay, Jeanmonod. Critically revising the article: all authors. Reviewed submitted version of manuscript: all authors. Approved the final version of the manuscript on behalf of all authors: Gallay. Statistical analysis: Gallay. Administrative/techni$\mathrm{cal} /$ material support: Moser.

\section{Supplemental Information \\ Online-Only Content}

Supplemental material is available with the online version of the article.

Supplemental Fig. 1 and Table 1. https://thejns.org/doi/suppl/ 10.3171/2019.12.JNS192219.

\section{Correspondence}

Marc N. Gallay: Center for Ultrasound Functional Neurosurgery, Solothurn, Switzerland.marc.gallay@gmail.com. 